that included probing depth (PD) and clinical attachment level (NIC) DCVI and was represented by one of the following outcomes: Coronary Artery Disease (CAD), Myocardial Infarction (AMI) with or without angina pectoris, or Acute Coronary Syndrome (ACS). The quality of the articles was assessed using criteria recommended in "The Strengthening the Reporting of Observational Studies in Epidemiology-STROBE". In addition, compliance with the guidelines of the guide to meta-analysis for observational studiesMOOSE.

Results Of the 23 studies, case-control eligible, 16 had their results combined using the methodology of meta-analysis. The overall OR was approximately 2.52 (95\% CI 2109 to $3009, \mathrm{p}<0.001)$, indicating that individuals with $\mathrm{PD}$ have an increased chance of developing ischaemic $\mathrm{CDH}$ as compared to those without $\mathrm{PD}$.

Conclusion Observational case-control suggest that individuals with $\mathrm{PD}$ are more likely to develop ischaemic $\mathrm{CDH}$, however, further studies are needed for more definitive conclusions.

\section{P2-46 ASSESSING THE HEALTH RELATED QUALITY OF LIFE AND EFFECTIVE FACTORS: A POPULATION BASED STUDY}

doi:10.1136/jech.2011.142976h.81

$1,20 ̈$ Ülger, ${ }^{2} \mathrm{M}$ Çöl. ${ }^{*}$ Ministry of Health, Ankara, Turkey, Turkey; ${ }^{2}$ Ankara University Medical Faculty, Ankara, Turkey, Turkey

Introduction This study has been planned to determine quality of life of people in one health center area, and the effect of sociodemographic factors, hypertension and other chronic diseases.

Methods This cross-sectional study is conducted among residence of age 40 and over, living at the Park Health Center Area in AnkaraTurkey. Three hundred participants from the eligible population $(\mathrm{n}=5962)$ were chosen by simple random sampling of these 260 $(86.6 \%)$ were reached. Twenty for questions for sociodemographic factors and chronic diseases and short form 36 (SF-36) health survey questionnaires had been administered to each participant. Data analysis was performed by using SPSS for Windows program, Mann-Whitney U, Kruskal-Wallis and multiple linear regression tests were used for statistical analysis.

Results The mean of general SF-36 score of the study group was $61.8 \pm 21.9$ (95\% CI 59.1 to 64.5$)$. The scores for physical functioning, physical role, bodily pain, general health, vitality, social functioning, emotional role and general mental health scales were (70.5), (57.8), (64.5), (54.6), (52.8), (77.9), (56.7), and (59.8) respectively. In multiple linear regression analysis; age, sex, education, type of house, annual income per capita, hypertension and the other chronic diseases had significant effect on various scales of the SF-36.

Conclusion The SF-36 scores of the study population were found to be low. It was determined that older age, female sex; low education level, hypertension and other chronic diseases have a negative effect on quality of life. According to results multidisciplinary approach and efforts are necessary for promoting quality of life.

\section{P2-47 INCREASING INCIDENCE OF BARRETT'S OESOPHAGUS: A POPULATION BASED STUDY IN NORTHERN IRELAND}

doi:10.1136/jech.2011.142976h.82

${ }^{1} \mathrm{H}$ Coleman, ${ }^{* 1} \mathrm{~S}$ Bhat, ${ }^{1} \mathrm{~L}$ Murray, ${ }^{2} \mathrm{D}$ McManus, ${ }^{1,3} \mathrm{~A}$ Gavin, ${ }^{2} \mathrm{~B}$ Johnston. ${ }^{1}$ Queen's University Belfast, Northern Ireland, UK; ${ }^{2}$ Belfast Health and Social Care Trust, Northern Ireland, UK; ${ }^{3}$ Northern Ireland Cancer Registry, Northern Ireland, UK

Introduction Oesophageal adenocarcinoma (OAC) incidence rates have increased in recent decades, particularly among white males in Western societies. Rising Barrett's oesophagus (BO) incidence, the pre-cursor condition for $\mathrm{OAC}$, may explain this phenomenon.
However, increasing BO incidence may also simply reflect changes in endoscopy practices together with improvement in disease recognition. The aim of our investigation was to assess $\mathrm{BO}$ incidence over a 13-year period using a population-based register in Northern Ireland. Methods The Northern Ireland Barrett's oesophagus Register is a population-based register of all adults diagnosed with $\mathrm{BO}$, defined as columnar epithelium of the oesophagus, in Northern Ireland between 1993 and 2005. Annual BO incidence rates were calculated per 100000 of the population, per 100 upper gastro-intestinal endoscopies and per 100 oesophageal biopsies performed in Northern Ireland.

Results During the 13-year period, 197635 patients underwent an endoscopy and 9329 of these were diagnosed with BO. Average annual $\mathrm{BO}$ incidence rates rose by 2.5-fold, increasing from 31.9/ 100000 during 1993-1997 to 80.1/100 000 during 2002-2005. Over the same time, there were 1.3- and 1.6-fold increases in endoscopy and biopsy rates in the population, respectively. Even with increasing rates of endoscopy and biopsy, BO was still diagnosed more frequently per 100 endoscopies and per 100 biopsies.

Conclusion BO incidence rates in Northern Ireland have increased more rapidly than the rate of endoscopies or biopsies. This could indicate that a true rise in $\mathrm{BO}$ incidence has occurred, contributing to the increase in OAC seen in Western populations.

\section{P2-48 SECULAR CHANGES OF OVERWEIGHT AMONG BRAZILIAN ADOLESCENTS: AN UPDATE}

doi:10.1136/jech.2011.142976h.83

W Conde, * C Monteiro. Public Health School, University of Sao Paulo, Sao Paulo, Brazil

Introduction Overweight in adolescents is worldwide and have been growing fast in the three last decades. In Brazil, data from three national surveys show that prevalence of overweight among male fivefold from 1974-1975 to 2002-2003 and flat among female from 1989 to $2002-2003$.

Objective To update changing trends of overweight among Brazilian adolescents across last 4 decades.

Methods Data are age-ranged 10-19 years and come from four nationwide surveys: ENDEF-1974-1975, PNSN-1989, POF2002-2003 and POF 2008-2009. Overweight was classified according to IOTF's purpose as the BMI values greater than the adult equivalent $25 \mathrm{~kg} / \mathrm{m}^{2}$ critical values. Change in risk of overweight across survey periods was estimated using ratio of prevalence (RR). Results Among boys, prevalence of overweight was 2.4, 5.7 and 13.2 and $17.3 \%$ at $1974-1975,1989,2002-2003$ and 2008-2009, respectively; among girl, prevalence of overweight was $6.0,11.8$, 12.5 and $16.3 \%$ at same survey, respectively. From 2002-2003 to 2008-2009 overweight increased across all age groups and income strata, both sexes. RR for changing trends from 1974-1975 to 1989 1989 to 2002-2003 and 2002-2003 to 2008-2009 among the fifth poorest male are 2.6, 7.5, 10.1, respectively and among the fifth richest male are 2.1, 3.3 and 4.4, respectively. Among the poorest female RR are: 2.1, 2.4 and 3.7 and among richest fifth are 2.01 .5 2.1 , respectively.

Conclusion In general, overweight expanded stronger in the last decade. Female adolescents in Brazil has reversed flat trend and are going to increase body mass index at all age and income strata.

\section{P2-49 SUBCLINICAL DIASTOLIC DYSFUNCTION IS ASSOCIATED WITH BIOMARKERS OF HEPATIC FUNCTION: RESULTS FROM THE STOP HF STUDY}

doi:10.1136/jech.2011.142976h.84

${ }^{1} \mathrm{C}$ Conlon, ${ }^{*} \mathrm{C}$ Kelleher, ${ }^{2} \mathrm{H}$ Ulmer, ${ }^{3}$ Dawkins, ${ }^{3} \mathrm{~A}$ Patle, ${ }^{3} \mathrm{C}$ O'Loughlin, ${ }^{3} \mathrm{M}$ Ledwidge, ${ }^{3} \mathrm{~K}$ McDonald. ${ }^{1}$ School of Public Health, Physiotherapy \& Population Science, University 